\title{
Flying activity and population dynamics of Cordulegaster heros Theischinger, 1979 (Insecta: Odonata: Cordulegastridae) in Slovakia
}

\author{
Attila Balázs ${ }^{\mathrm{a} *}$, Zdeněk F. Fric ${ }^{\mathrm{b}}$ and Otakar Holuša ${ }^{\mathrm{c}}$ \\ ${ }^{a}$ Department of Zoology, Fisheries, Hydrobiology and Apiculture, Faculty of AgriSciences, Mendel \\ University in Brno, Brno, Czech Republic, ${ }^{b}$ Biology Centre CAS, Institute of Entomology, Ceske \\ Budejovice, Czech Republic; ${ }^{c}$ Department of Forest Protection and Wildlife Management, Faculty of \\ Forestry and Wood Technology, Mendel University in Brno, Brno, Czech Republic
}

(Received 30 August 2019; accepted 3 March 2020 )

\begin{abstract}
In 2017, we investigated the population dynamics and flying activity of the south-east European endemic dragonfly species Cordulegaster heros Theischinger, 1979. This research was conducted in the southern part of Central Slovakia in the Revúcka vrchovina Upland at a submountainous stream called Drienok. The mark-release-recapture method was applied to study the population. Cordulegaster heros was observed 775 times during the midsummer season. We found out that the species has bimodal diurnal activity pattern with a highest peak from 17:00 until 19:00 hours, but the species had a short peak before noon as well. The differences between sexes in the sense of entering new individuals to the population were low during the main flying period. Estimated population size for males surpassed the population size of females. Probability of capture decreased by the end of the flying season without differences in sexes. This article is the first on the flying activity and population dynamics of Cordulegaster heros.
\end{abstract}

Keywords: dragonfly; Anisoptera; Revúcka vrchovina Upland; mark-release-recapture; Carpathian streams

\section{Introduction}

Cordulegaster heros Theischinger, 1979 is a flagship species of dragonfly observed in closed riverine habitats at low altitudes in the Carpathian Mountains. The habitat requirements of this species are fairly well known (Boudot \& Kalkman, 2015), but its distribution across Slovakia or, more specifically, in the Carpathians is still not well understood (Holuša \& Kúdela, 2010). There is also little knowledge of the species' population in particular habitats in Slovakia. To gain insight into the species' population dynamics, we set out an experiment based on markrelease-recapture methods (MRR).

Mark-release-recapture methods are commonly used in various entomological studies to estimate population dynamics. For example, they can serve as an estimation tool for survival of adult caddisflies (White \& Henschen, 1978), to calculate dispersal abilities of threatened butterflies (Fric, Hula, Klimova, Zimmermann, \& Konvicka, 2010) or to detect biological changes in

*Corresponding author. Email: balazsaeko@gmail.com 
host species attacked by infections (Caragata, Real, Zalucki, \& McGraw, 2011). Odonates (dragonflies and damselflies) are similarly suitable for mark-release-recapture studies. The efficacy of these methods has been demonstrated over several decades (Anholt, 1997; Cordero-Rivera, 2016; Cordoba-Aguilar, 1994; Michiels \& Dhondt, 1991; Ubukata, 1981). The body size of odonates, together with their occurrence in relatively isolated populations at high densities, allows high recapture rates and makes them model organisms for recapture and radio telemetric studies. This is particularly relevant for species restricted to creeks and streams in forest complexes (Corbet, 2004; Kortello \& Ham, 2010; Laister, 2012; Lang, Müller, \& Waringer, 2001; Moskowitz \& May, 2017; Ribeiro Loiola \& De Marco, 2011; Rivas-Torres, Sanmartín-Villar, Gabela-Flores, \& Cordero-Rivera, 2017).

The only odonate family in Europe confined to lotic water in forested habitats is Cordulegastridae (Boudot \& Kalkman, 2015). Representatives of this family are among the biggest dragonflies (Holuša, 2013). The adults are persistent flyers, the males attentively patrolling a few tens of centimetres above the water and vigorously chasing off their conspecifics or searching for females. Females can be found resting in the tree canopy, ovipositing or foraging to avoid male sexual harassment (Dijkstra \& Lewington, 2014). Cordulegastridae are represented in Slovakia by two species. The crenophilous Cordulegaster bidentata Selys, 1843 has a disjunctive distribution in central and southern Europe and is confined to higher altitudes in mountainous area of the Carpathians (Fekete \& Ézsöl, 2016; Holuša \& Holušová, 2014). The other species, Cordulegaster heros, which we selected as our model organism for this study, is an endemic European species occurring in the Balkan Peninsula, from Greece through Albania, North Macedonia, Bulgaria, Montenegro, Bosnia and Herzegovina, Serbia, Croatia, Slovenia, Austria, and Italy to the eastern part of Central Europe, including The Czech Republic, Slovakia, Hungary and Ukraine (Bernard \& Daraź, 2015; Dijkstra \& Lewington, 2014; Staufer \& Holuša, 2010). As the species has valuable indicator features of pristine water flows, it figures in Annexes II and IV of the European Habitat Directive of Council Directive No. 92/43/EEC. In Slovakia the species is restricted to lower altitudes (ranging from approximately $200 \mathrm{~m}$ to $500 \mathrm{~m}$ asl) than its congeneric species. It inhabits clear water streams with a depth ranging from a few millimetres to several tens of centimetres, and width varying from $20 \mathrm{~cm}$ to a maximum measured $420 \mathrm{~cm}$ (Boda et al., 2015; Holuša \& Kúdela, 2010). Tantalizingly little is known about the flying season, survival rates or the prereproductive period for all Cordulegastridae species in the Western Palaearctic region.

We assume that Cordulegaster heros will have a later flying season on account of the increased latitude of the Carpathians in relation to Greek populations and that their flying season should be shortened. Taking account of Corbet (2004), diurnal pattern can vary with regards to age, sex, habitat, climate, weather, and abundance of conspecifics. The species' eocrepuscular aspects are known; however, to our knowledge, data in this article are the first to be published dealing with diurnal activity of a Cordulegaster species. Bearing this in mind, we hypothesize that $C$. heros will have bimodal diurnal activity with morning and afternoon placement of activity maxima (Corbet, 2004).

In this study, our aims were (i) to establish the diurnal pattern of activity and (ii) to estimate the abundance of the adult population during its flight season.

\section{Methods}

\section{Sampling}

The study of the stream's population of $C$. heros commenced on 9 June 2017 and was completed on 30 July 2017. During this period we recorded on a total of 11 days from 05:00 to 21:00 $(\mathrm{GMT}+1)$. The capture point (where marking of the insects took place) was fixed and consistent 


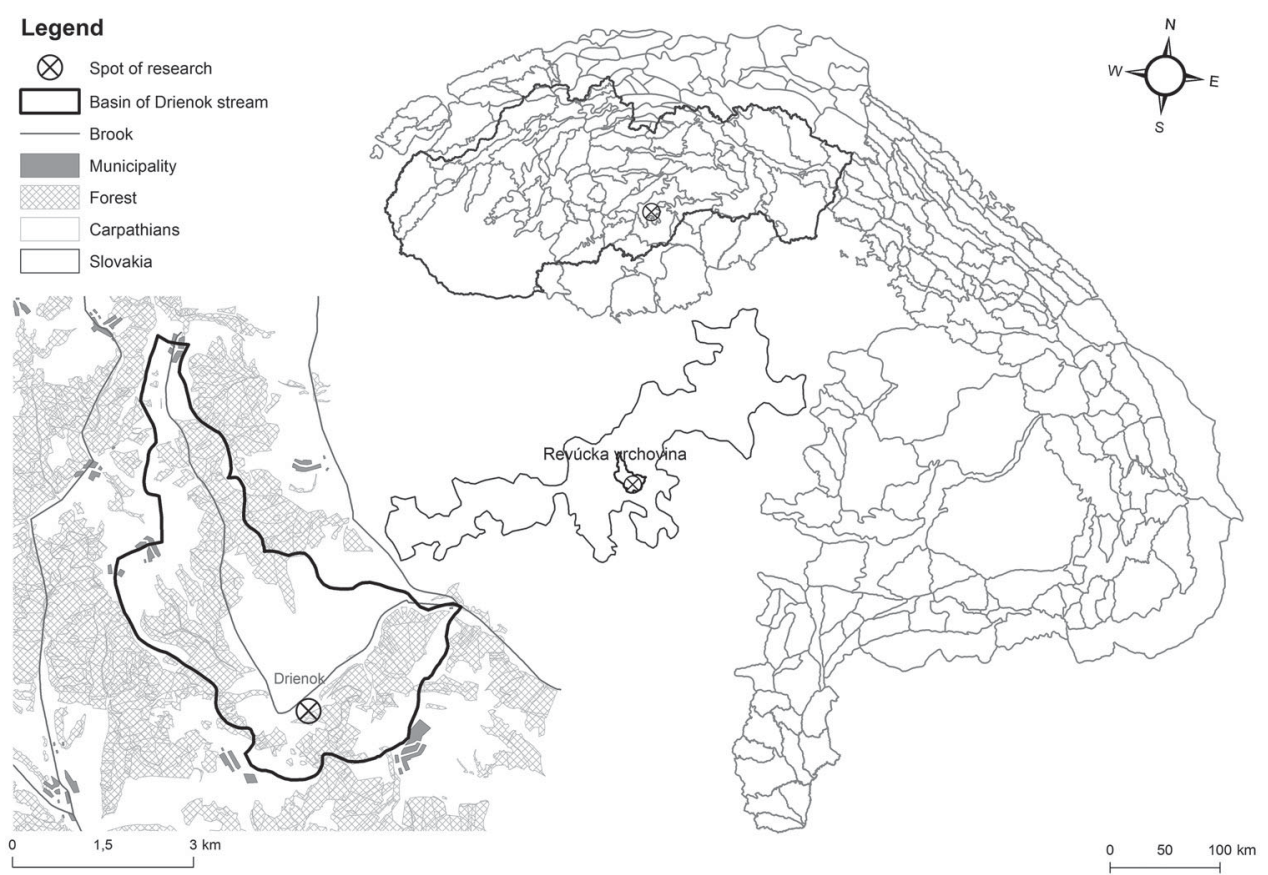

Figure 1. Map showing where the research was conducted in the south of Central Slovakia, in Revúcka vrchovina Highland at Rybník village.

during the whole study. This point was selected as it provided a clear view for approximately $10 \mathrm{~m}$ in both directions. Specimens were captured using a butterfly net with opening diameter of $40 \mathrm{~cm}$ on a $3.5 \mathrm{~m}$ long stick. The individuals were marked on the right hind wing by permanent marker using unique numeric characters and immediately released to reduce damage or stress effects. Only adults of reproductive maturity were marked. Recaptured individuals marked on the same day were not considered as a recapture event. Legitimately recaptured individuals are described below as exemplars for which three parameters were noted: (i) direction of the flight (along or against the stream), (ii) type of flight (patrolling, fast, oviposition) and (iii) time of recapture (date and time).

\section{Study area}

The research was conducted in the south of Central Slovakia, in Revúcka vrchovina Highland at Rybník village on a sub-mountainous stream (Figure 1). The spot (48.5293342N, 20.1035628E) is situated at Drienčaský kras Mts which is an island of limestone with the area of $23 \mathrm{~km}^{2}$ between Slovenský kras and Muránska planina. Forest communities are represented by mesophilousto-subxerophilous oak-hornbeam forests (alliance Carpinion betuli). Submontane beech forest (Eu-Fagenion) and ravine forest (Tilio-Acerion) associations are confined to habitats with more diverse landforms. At the floodplains, Angelico sylvestri-Alnetum glutinosae and MatteuccioAlnetum glutinosae are present. Broad-leaved riparian herb populations such as Petasitetum hybridi occur in mosaic inside the submontane alder forest, documented in the basin of the Drienok creek, where our research was performed (Chytrý, Kučera, Kočí, Grulich, \& Lustyk, 2010). 


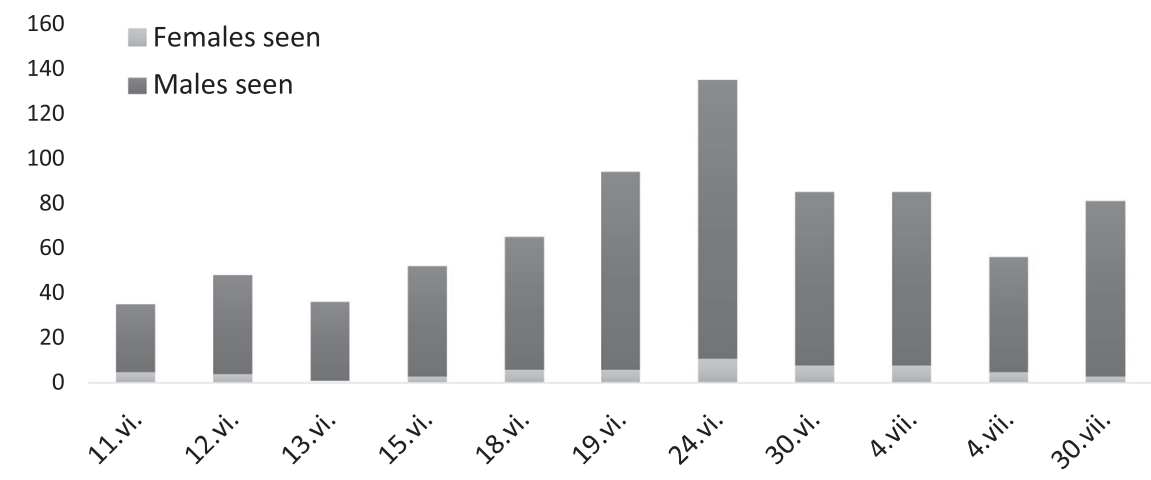

Figure 2. Numbers of individuals of Cordulegaster heros in June and July 2018.

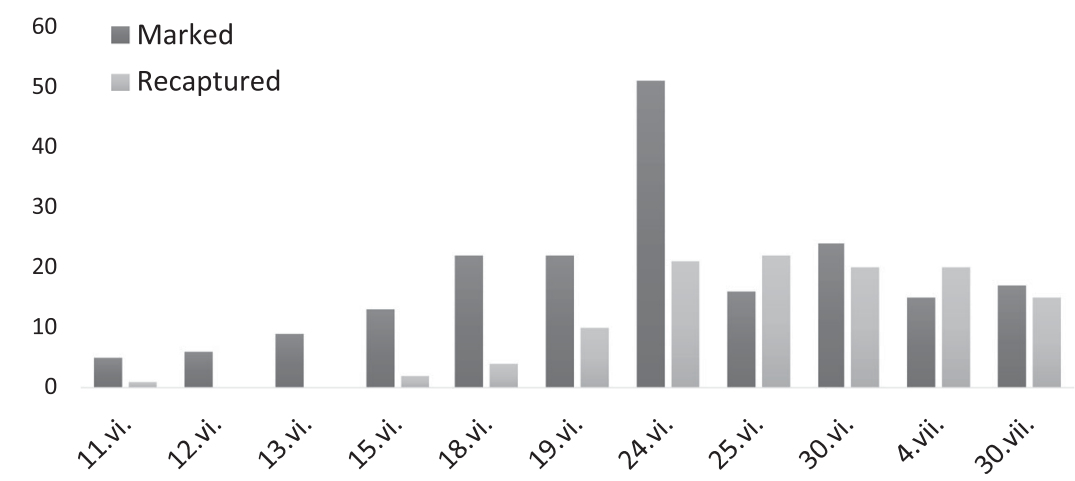

Figure 3. Numbers of marked and recaptured specimens of Cordulegaster heros in June and July 2018.

\section{Population estimates}

We analysed the mark-release-recapture data in Mark (version 8.2), using POPAN model (Cooche \& White, 2010). Here we estimated the following population parameters: survival (phi), probability of capture (p), probability of entering population (pent) and estimated population size $(\mathrm{N})$. All these parameters could have several responses. They could have been constant (.), differing between sexes $(\mathrm{g})$, differing in time within same sex $(\mathrm{t})$, changing in time and sexes $(\mathrm{g} \times \mathrm{t})$ or changing in time but with sex differences only in magnitude levels $(g+t)$. We compared different models using AICc values, where the lowest value indicated the most suitable model in the sense of explanatory power and model complexity.

\section{Results and discussion}

Altogether, during the research, C. heros was observed 775 times, of which 713 were males, and only 62 females (Figure 2). The day with the least recorded exemplars was 11 June 2017, when we observed 29 males and 5 females. The most successful day was 24 June 2017, when 124 males and 11 females were observed. The overall number of captured individuals is 215,188 males and 27 females (Figure 3). Altogether 80 males were recaptured at least once, 17 twice and 4 males three times. Three females were recaptured once. The longest period between marking and the latest recapture of the same individual was 36 days. 


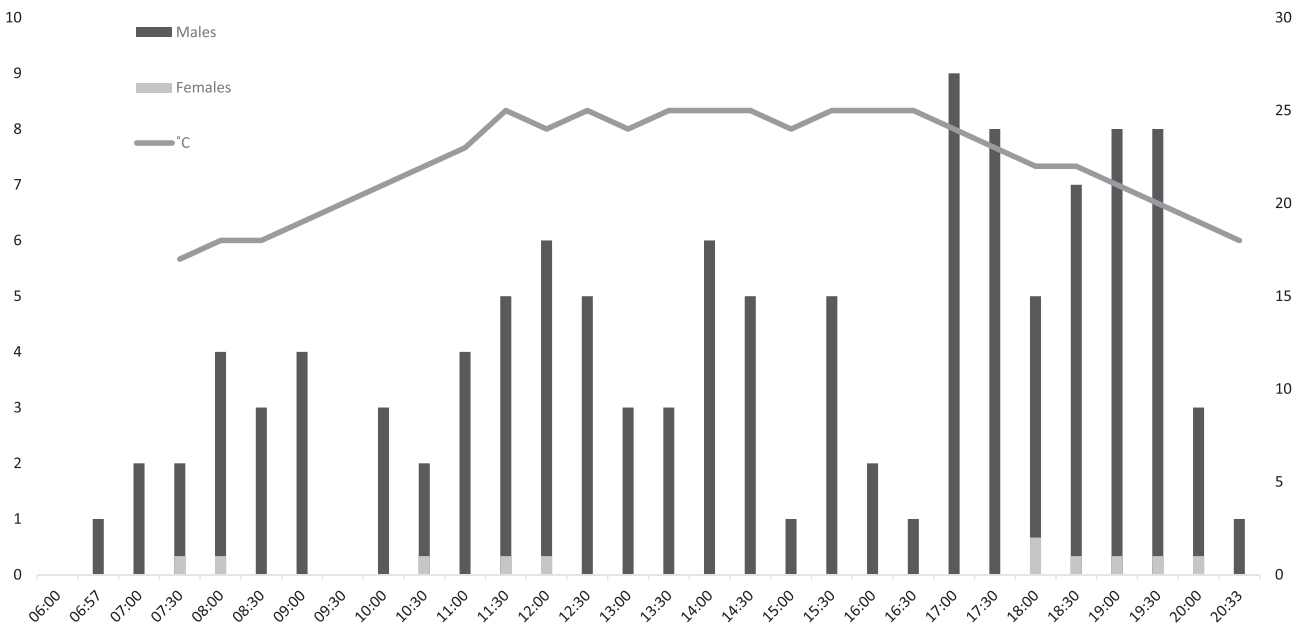

Figure 4. Diel variation of Cordulegaster heros in relation to air temperature on 24 June 2017 in Drienok, Slovakia.

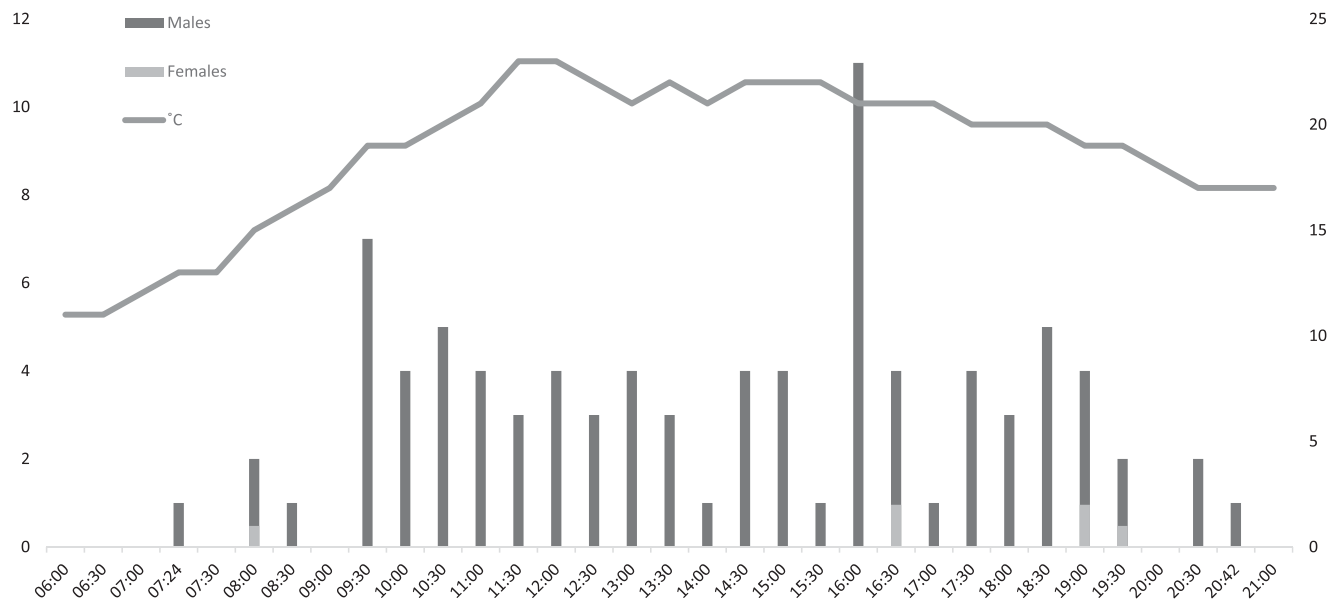

Figure 5. Diel variation of Cordulegaster heros in relation to air temperature on 19 June 2017 in Drienok, Slovakia.

\section{Flying activity}

The earliest flight of a male was observed on 24 June 2017 at 06:57, the latest flight on record was on 19 July 2017 at 20:42 p.m. The flying activity of Cordulegaster heros followed a bimodal diurnal pattern intensifying during the day. Nevertheless, reduced periods of activity occurred approximately from 09:00 to 10:00, then in the afternoon from 15:00 until 17:00 (Figure 4). The expected bimodal diurnal activity pattern was confirmed clearly on 19.vi. (Figure 5), less significantly on 24.vi., but on 30.vi. there was evidence for unimodal diel pattern (Figure 6) since most individuals were observed late afternoon from 17:00. to 18:30, but no enhanced activity during the day. Similar results were obtained by Müller (1999) during two seasons in 1997 and 1998. Müller observed 115 individuals of $C$. heros and $C$. bidentata of which only 16 were females. 


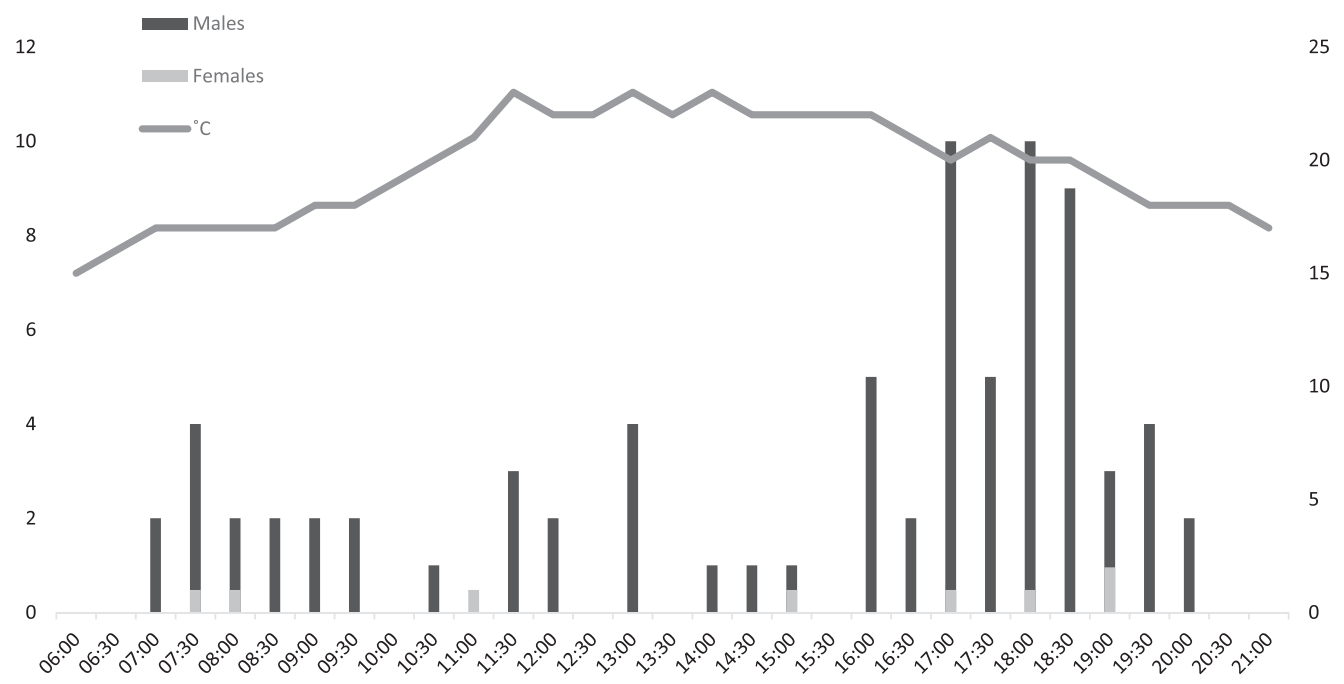

Figure 6. Diel variation of Cordulegaster heros in relation to air temperature on 30 June 2017 in Drienok, Slovakia.

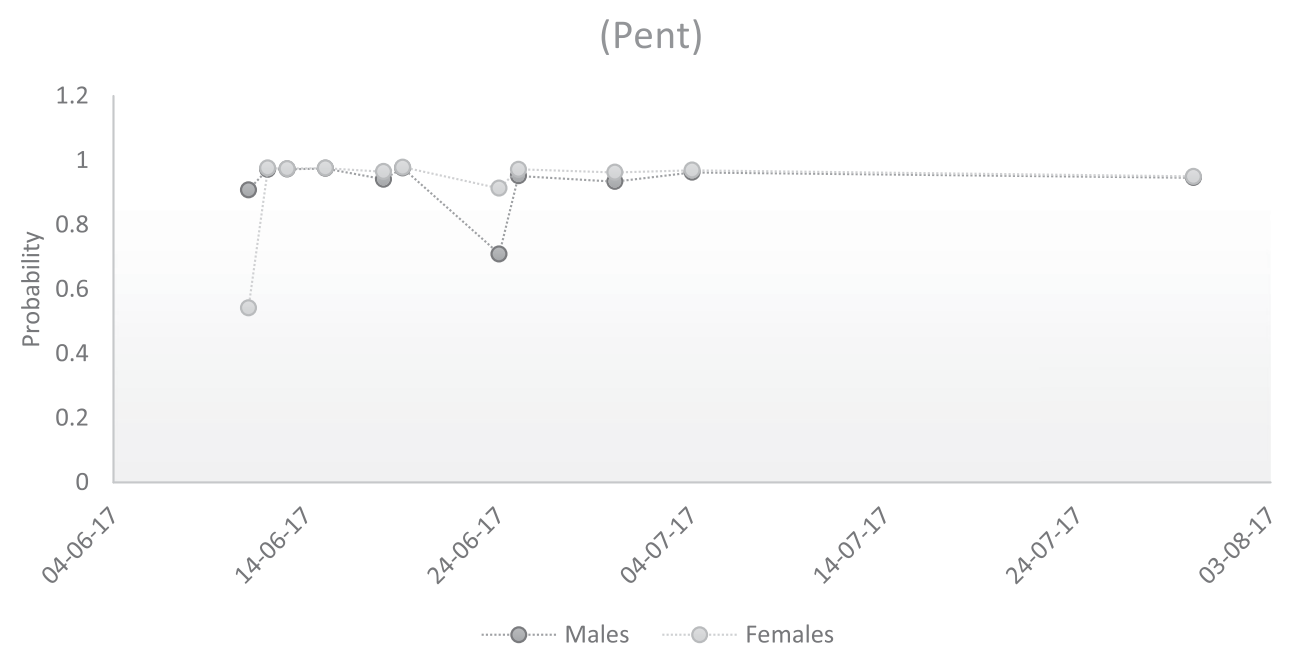

Figure 7. Probability of entering population (pent) of Cordulegaster heros in Drienok, Slovakia.

\section{Epigamic behaviour}

Our research demonstrates that males searched along the stream for females approximately from 07:00 until 20:00 hours. Their slow patrol flight, ca. $30 \mathrm{~cm}$ above stream, allows them to examine all details of the habitat. Males often encountered females during oviposition. After recognition, the male aggressively grabs the female's prothorax and they quickly fly away from the stream high into the canopy. Females lay eggs directly to the fine sediment of the shallower section of the stream. The abdomen of the female is terminated with stylets richly equipped with numerous sensilla to insert the eggs correctly into the substrate during oviposition. The first oviposition was recorded on 11 June 2017 at 06:59. The female dipped her abdomen three times during $2 \mathrm{~s}$, then flew away. The longest oviposition observed was on 24 June 2017 and lasted 46 seconds at 7:00. The oviposition seen on 19 July 2017 at 19:47 lasted 10s with 25 stabs of the abdomen. The latest oviposition was observed on 30 July 2017 at 19:16. The best observations on the flying patterns of $C$. heros were made near water. Unfortunately, due to the species' cryptic behaviour 


\section{(Phi)}

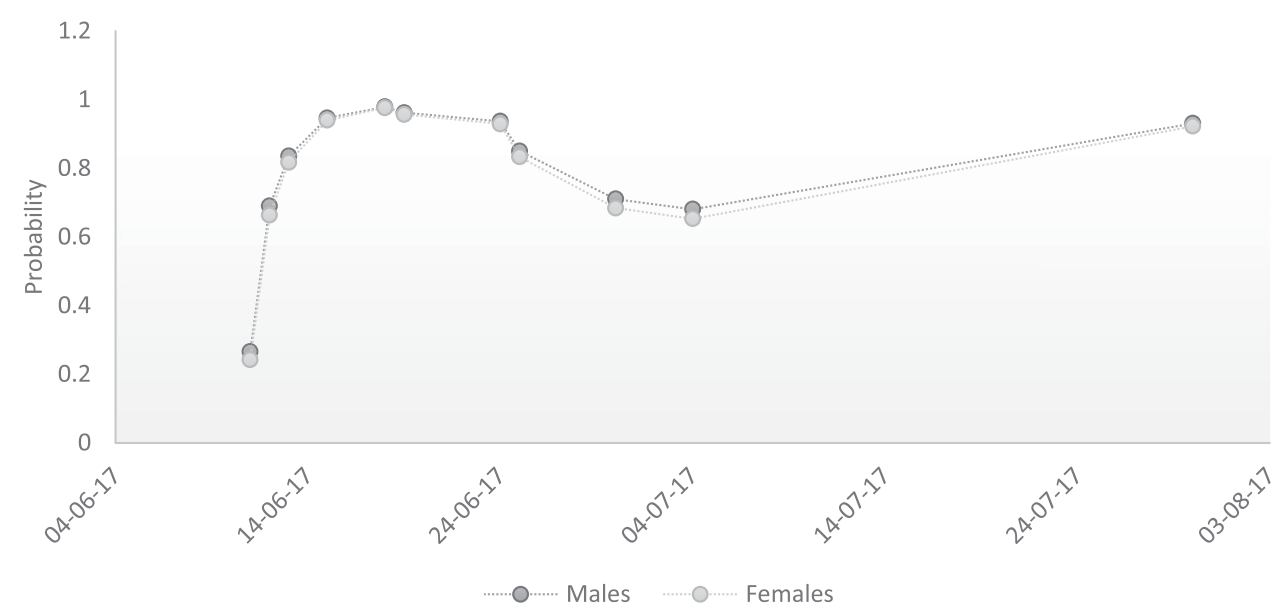

Figure 8. Probability of survival (Phi) of marked specimens of Cordulegaster heros in Drienok, Slovakia.

(p)

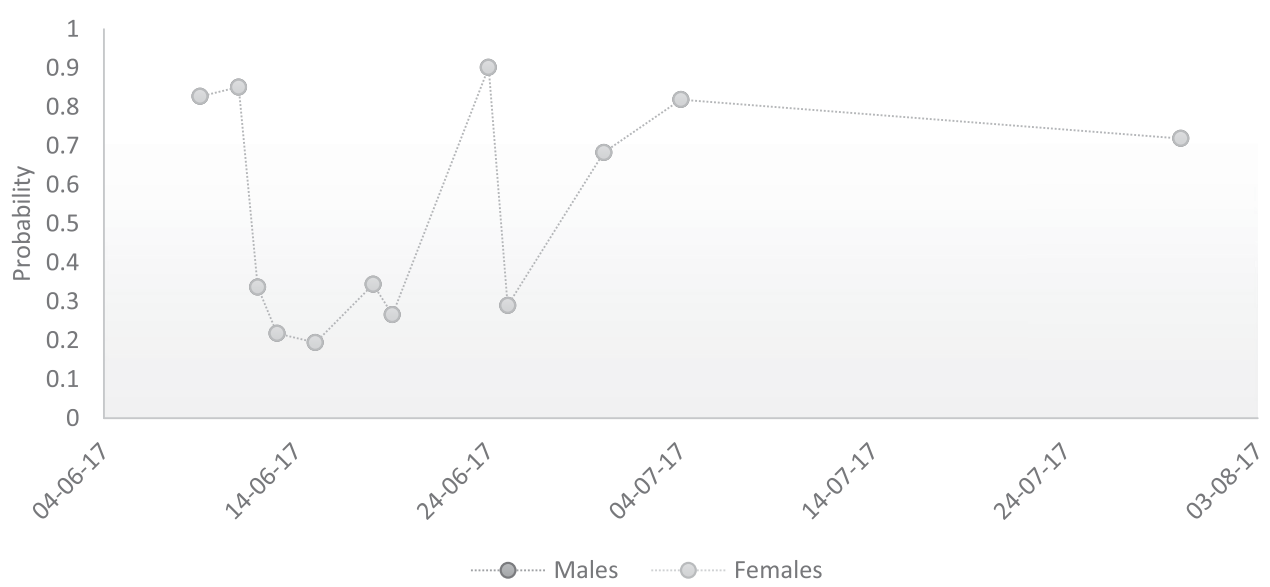

Figure 9. Probability of capturing specimens (p) Cordulegaster heros in Drienok, Slovakia.

we were not able to observe other activities such as the time period of copula, foraging behaviour, and post-copulatory behaviour.

\section{Mark-release-recapture data}

The most favoured model was rather complex, revealing time and sex differences in the majority of the parameters. The other models were simpler but did not adequately explain the data. The pent values indicated high number of new animals entering the population in the main season; the differences between sexes were small (Figure 7). Estimated population size for males $(\mathrm{N}=216.87)$ greatly exceeded the estimate for females $(\mathrm{N}=34.65)$. Due to the complexity of the model, no standard error value was estimated. The values of phi were relatively high (Figure 8), and very similar in males and females; these gradually increased, forming a peak 
around the mid flying season. Probability of capture decreased during the main season, and there was no differences in the sex (Figure 9).

\section{Acknowledgements}

Many thanks go to Ing. Veronika Rízová (PLA Cerová vrchovina Upland) for creating the map.

\section{Funding}

This research was financially supported by the grant IGA FA MENDELU No. IP_60/2017, "Faunistic and ecological assessment of species of genus Cordulegaster and Sympetrum (Insecta: Odonata) in selected areas of Slovakia".

\section{References}

Anholt, B. R. (1997). Sexual size dimorphism and sex-specific survival in adults of the damselfly Lestes disjunctus. Ecological entomology, 22, 127-132.

Bernard, R., \& Daraź, B. (2015). Cordulegaster heros and Somatochlora meridionalis in Ukraine: Solving the zoogeographical puzzle at their northern range limits. Odonatologica, 44(3), 255-278.

Boda, R., Bereczki, Cs., Ortmann-Ajkai, A., Mauchart, P., Pernecker, B., \& Csabai, Z. (2015). Emergence behaviour of the red listed Balkan Goldenring (Cordulegaster heros Theischinger, 1979) in Hungarian upstreams: Vegetation structure affects the last steps of the larvae. Journal of Insect Conservation, 19, 547-557.

Boudot, J.-P., \& Kalkman, V. J. (Eds.). (2015). Atlas of the Dragonflies and Damselflies of Europe. Utrecht: KNNV.

Caragata, E. P., Real, K. M., Zalucki, M. P., \& McGraw, E. A. (2011). Wolbachia infection increases recapture rate of field-released Drosophila melanogaster. Symbiosis, 54(1), 55-60.

Chytrý, M., Kučera, T., Kočí, M., Grulich, V., \& Lustyk, P. (Eds.). (2010). Katalog biotopů České republiky. Ed. 2. Praha: Agentura ochrany prrírody a krajiny ČR.

Cooch, E., \& White, G. (2010). Program MARK: a gentle introduction (9th ed.). http://www.phiorg/software/mark/docs/ book/.

Corbet, P. S. (2004). Dragonflies: Behaviour and Ecology of Odonata. Colchester: Harley Books, 829.

Cordero-Rivera, A. (2016). Sperm removal during copulation confirmed in the oldest extant damselfly, Hemiphlebia mirabilis. PeerJ, 4:e2077. DOI 10.7717/peerj.2077

Córdoba-Aguilar, A. (1994). Adult survival and movement in males of the damselfly Hetaerina cruentata (Odonata: Calopterygidae). Florida Entomologist, 77(2), 256-264.

Dijkstra, K. D. B., \& Lewington, R. (2014). Field guide to the dragonflies of Britain and Europe. Gillingham: British Wildlife Publishing.

Fekete, J., \& Ézsöl, T. (2016). Adatok a hegyiszitakötő (Cordulegaster bidentate Selys, 1843) bükki előfordulásához. Studia odonatologica hungarica, 18, 85-93.

Fric, Z., Hula, V., Klimova, M., Zimmermann, K., \& Konvicka, M. (2010). Dispersal of four fritillary butterflies within identical landscape. Ecological Research, 25, 543-552.

Holuša, O. (2013). Taxonomie, ekologie a zoogeografie vážek rodu Cordulegaster (Odonata: Cordulegastridae) ve střední Evropě. [Disertační práce]. Prírodovedecká fakulta, Univerzita Komenského v Bratislave, 176 pp.

Holuša, O., \& Holušová, K. (2014). První nález Cordulegaster bidentata (Odonata: Cordulegastridae) v Cerové vrchovině na Slovensku. Acta Musei Beskydensis, 6, 77-82.

Holuša, O., \& Kúdela, M. (2010). New records of occurrence of Cordulegaster heros Theischinger, 1979 in Slovakia. Acta Musei Beskydensis, 2, 75-87.

Kortello, A. D., \& Ham, S. J. (2010). Movement and habitat selection by Argia vivida (Hagen) (Odonata, Coenagrionidae) in fuel-modified forest. Journal of Insect Conservation, 14, 133-140. DOI 10.1007/s10841-009-9233-2.

Laister, G. (2012). Ortsreue und Gewässerwechsel von Cordulegaster boltonii (Odonata: Cordulegastridae). Libellula, 31(3/4), 113-130.

Lang, C., Müller, H., \& Waringer, J. A. (2001). Larval habitats and longitudinal distribution patterns of Cordulegaster heros Theischinger and $C$. bidentata Sélys in an Austrian forest stream (Anisoptera: Cordulegastridae). Odonatologica, 30(4), 395-409.

Michiels, N. K., \& Dhondt, A. A. (1991). Characteristics of dispersal in sexually mature dragonflies. Ecological Entomology, 16, 449-459.

Moskowitz, D., \& May, M. (2017). Adult tiger spiketail (Cordulegaster erronea Hagen) habitat use and home range observed via radio-telemetry with conservation recommendations. Journal of Insect Conservation, 21, $885-895$.

Müller, H. (1999). Phänologie und Ökologie der Imagines von Cordulegaster heros Theischinger, 1979 und Cordulegaster bidentata Selys, 1843 (Insecta: Odonata) am Weidlingbach (Niederösterreich). Unveröff. Diplomarbeit an der Universität Wien, 1-89. 
Ribeiro Loiola, G., \& De Marco, P. (2011). Behavioral ecology of Heteragrion consors Hagen (Odonata: Megapodagrionidae): a shade-seek Atlantic forest damselfly. Revista Brasileira de Entomologia, 55(3), 373-380.

Rivas-Torres, A., Sanmartín-Villar, I., Gabela-Flores, M. V., \& Cordero-Rivera, A. (2017). Demographics and behaviour of Heteragrion cooki, a forest damselfly endemic to Ecuador (Odonata). International Journal of Odonatology, 20(2), 123-135, DOI: 10.1080/13887890.2017.1336495

Staufer, M., \& Holuša, O. (2010). First record of Cordulegaster heros in the Czech Republic, with notes on Cordulegaster spp. in southern Moravia (Odonata: Cordulegastridae). Libellula, 29(3/4), 197-204.

Ubukata, H. (1981). Survivorship curve and annual fluctuation in the size of emerging population of Cordulia aenea amurensis Selys (Odonata: Corduliidae). Japanese Journal of Ecology, 31, 335-346.

White, D. D., \& Henschen, M. T. (1978). A mark-recapture method for adult caddisflies (Insecta: Trichoptera). The Southwestern Naturalist, 23 3, 33-536. 